\title{
The Effects of the Natural Components on the Ageing of the Italian Population
}

\author{
Giuseppina Sacco \\ Pietro Sacco
}

University of Bari, Department of Economics and Finance, Italia

Doi: 10.19044/esj.2018.v14n2p221 URL:http://dx.doi.org/10.19044/esj.2018.v14n2p221

\begin{abstract}
The most remarkable demographic changes that have been happening in our society, and causing considerable social effects, are the significant decrease of fecundity and the increase of average life expectancy at birth. The combined effect of these factors causes the ageing of population, thus representing the theoretical basis of the phenomenon under study in this essay. We will analyse the evolution of fecundity in Italy and in Italian single regions , thus highlighting the change of its intensity over the years. Moreover, we will focus on the analysis of average life expectancy at birth by verifying both its time trend and how it changes because of the variations of mortality by age. Thanks to a suitable method, detailed data of ISTAT and EUROSTAT will be used to show the interesting findings of the fecundity geography and variations of mortality by age.

Nowadays, compared to just over twenty years ago, we have been characterized a reversal of the fecundity geography. Furthermore, a new increase of life expectancy at birth a further increase has been achieved.
\end{abstract}

Keywords: Italy, fecundity, average life expectancy at birth

\section{Variation in fecundity}

It is well-known that fecundity has been showing a decreasing trend for many years, thus increasing the imbalance of the structure by age. The evident consequence is the gradual impoverishment of the juvenile classes that causes what demographers call "ageing at the bottom" of the age pyramid.

The most used synthetic index of fecundity that measures the intensity of the phenomenon through the "cross-sectional" approach is the gross rate of total reproduction or TFR (total fertility rate). This rate shows the average number of children that a woman will have during all her estimated period of fecundity (15-49 years old). 
In Chart 1 there are the values of TFR in Italy from 1955 to 2015. They are graphically shown in Diagram 1.

\begin{tabular}{|l|l|}
\hline Years & TFR \\
\hline 1955 & 2.33 \\
1960 & 2.41 \\
1965 & 2.67 \\
1970 & 2.42 \\
1975 & 2.21 \\
1980 & 1.68 \\
1985 & 1.45 \\
1990 & 1.36 \\
1995 & 1.18 \\
2000 & 1.26 \\
2005 & 1.34 \\
2010 & 1.45 \\
2015 & 1.35 \\
\hline
\end{tabular}

Source: Istat

As one can infer from the chart, there is a remarkable decreasing trend of the values: in 1955 the TFR was equal to 2.33 children per woman while it decreases to 1.35 in 2015 . This is a significant decrease by $42.1 \%$.

The fecundity rate in 2015 is lower than the threshold level of 2.1 children per woman that allows the mother/daughter generational mobility in order to keep a stationary situation of the population. ${ }^{11}$

From Diagram 1 one can infer that the evolution of fecundity in Italy can be divided into three different stages:

first stage: a boom in births over the years until 1965. At the top of this stage in Italy there is the highest total fecundity rate (TFR) of the whole period under study (1955-2015) that is equal to 2.67 children per woman;

second stage: decrease from 1965 to 1995 . During this stage the scenario changes, because a second demographic transition is caused by deep sudden changes in the family and reproductive structures. In 1977 the TFR went below the substitution level for the first time and in 1995 Italian women reached the lowest fecundity rate equal to 1.18 children per woman. The births of alive children decrease from 1,035,000 in 1965 to 526,000 in 1995;

\footnotetext{
11 The three well-known combinations of the TFR levels:

TFR > 2.1 the generation of daughters is larger than that of the mothers: for this reason it can replace the generation of the mothers and guarantee the expansion of population as well. TFR $=2.1 \quad$ the two generations are like each other, which can guarantee only the substitution of the generation of mothers and consequently the tendential constancy of the population dimension.

TFR $<2.1$ the generation of daughters is less large than that of the mothers: for this reason the generation of daughters is not able to guarantee the substitution of the mothers' one and so the population is potentially in decline.
} 
third stage: beginning of a new countertendency whose last recorded value reached 1.35 children per woman with a peak of 1.45 children per woman in 2010.

Diagram 1 - Total Fecundity Rates

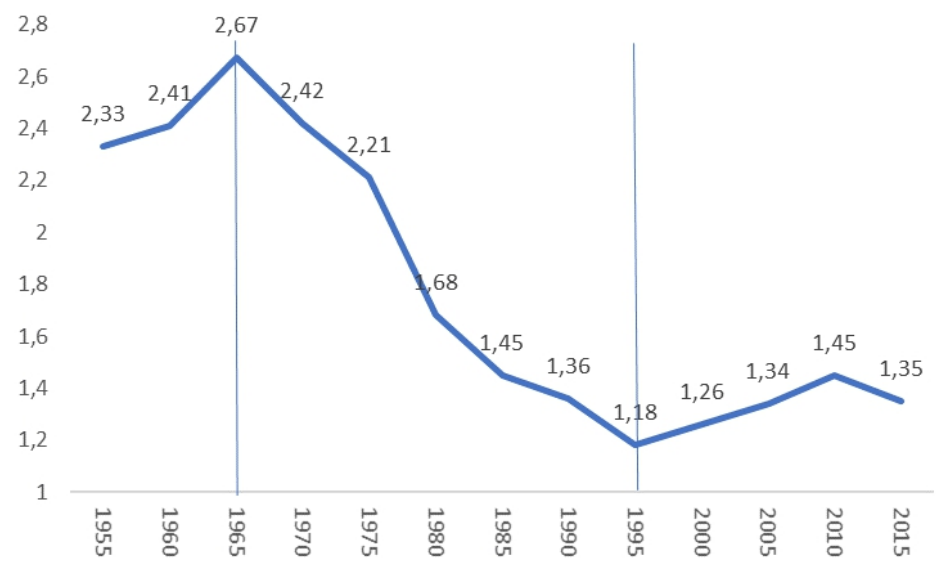

This raises the authors' question as to what happened at the beginning of the 1990s in Italy.

The data of Chart 2 show that at the beginning of the 1990s Italy was living its "second demographic transition", whose national TFR level was equal to 1.36. The regional levels varied from the minimum of 1.01 in Liguria and Emilia Romagna up to the maximum of 1.85 in Sicilia.

Even if the levels of the TFR were low (below the substitution threshold), fecundity increased more and more until 1995, when the TFR level reached its lowest level of 1.18. As far as the single regions are concerned the lowest level belongs to Liguria (0.94) and the highest to Campania (1.52).

After 1995 and considering the most recent data one can infer:

1. a reversal of trend of the fecundity rate and its increase in the northern regions where it has always been more moderate compared to that of the southern ones. Consequently, as far as fecundity is concerned, there has been an attenuation of the gap between the North and the South of Italy (Diagram 2)

2. the increase of fecundity in the northern regions caused a historical change: the highest value of TFR belongs to a northern region now (TrentinoAlto Adige 1.63) while the lowest to Sardegna (1.09). 
Chart 2- Total Fecundity Rates per region

\begin{tabular}{lllllll}
\hline Regions & 1990 & 1995 & 2000 & 2005 & 2010 & 2015 \\
\hline Piemonte & 1.10 & 1.04 & 1.17 & 1.27 & 1.40 & 1.36 \\
Valle d'Aosta & 1.18 & 1.09 & 1.27 & 1.35 & 1.61 & 1.40 \\
Lombardia & 1.15 & 1.07 & 1.21 & 1.35 & 1.52 & 1.44 \\
Trentino-Alto Adige & 1.40 & 1.34 & 1.46 & 1.54 & 1.62 & 1.63 \\
Veneto & 1.16 & 1.07 & 1.22 & 1.35 & 1.46 & 1.38 \\
Friuli-Venezia Giulia & 1.03 & 0.95 & 1.10 & 1.24 & 1.41 & 1.32 \\
Liguria & 1.01 & 0.94 & 1.03 & 1.18 & 1.32 & 1.30 \\
Emilia-Romagna & 1.01 & 0.97 & 1.17 & 1.34 & 1.49 & 1.42 \\
Toscana & 1.08 & 0.99 & 1.12 & 1.27 & 1.38 & 1.30 \\
Umbria & 1.18 & 1.08 & 1.17 & 1.32 & 1.37 & 1.27 \\
Marche & 1.23 & 1.11 & 1.18 & 1.28 & 1.39 & 1.33 \\
Lazio & 1.28 & 1.11 & 1.19 & 1.27 & 1.39 & 1.32 \\
Abruzzo & 1.39 & 1.19 & 1.16 & 1.21 & 1.32 & 1.28 \\
Molise & 1.42 & 1.22 & 1.15 & 1.14 & 1.20 & 1.17 \\
Campania & 1.81 & 1.52 & 1.48 & 1.43 & 1.42 & 1.34 \\
Puglia & 1.65 & 1.38 & 1.35 & 1.28 & 1.32 & 1.24 \\
Basilicata & 1.66 & 1.31 & 1.25 & 1.15 & 1.18 & 1.17 \\
Calabria & 1.74 & 1.40 & 1.26 & 1.24 & 1.28 & 1.29 \\
Sicilia & 1.85 & 1.49 & 1.41 & 1.41 & 1.40 & 1.35 \\
Sardegna & 1.37 & 1.06 & 1.06 & 1.05 & 1.16 & 1.09 \\
Italy & 1.36 & 1.18 & 1.26 & 1.34 & 1.45 & 1.35 \\
\hline
\end{tabular}

Diagram 2 Total Fecundity Rates per macro-areas

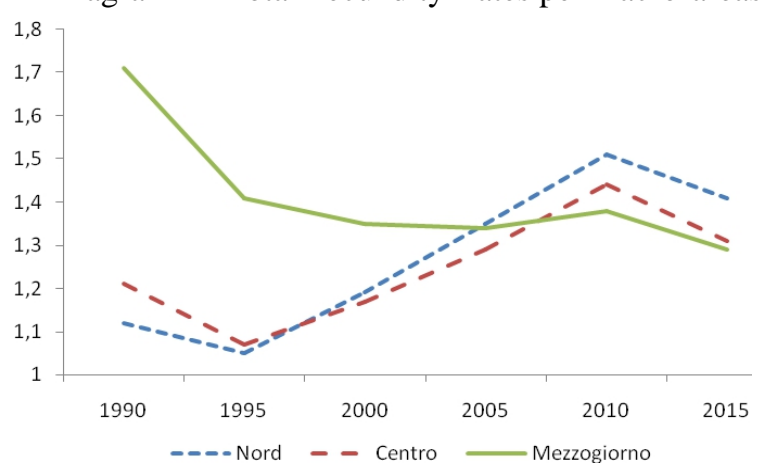

This raises the authors' question as to what caused this slight increase of fecundity. What has certainly modified the reproductive scenario in Italy has been the fecundity of foreign mothers. In fact, Italy, which has been an emigratory country for several decades, has been suffering a remarkable immigratory pressure especially in the northern regions.

In Chart 3 there is the total number of the born alive in Italy and the total number of the born-alive children who were born to a mother having a foreign citizenship. All that in order to determine the incidence of this kind of 
births on the total number of the born alive during the period of the third stage, 2000-2015, which was affected by an increase of fertility.

What is evident is that the born alive to a foreign mother increased from 35,001 in 2000 to 94,269 in 2015 . This increase is equal to $169.3 \%$; therefore, during this 15 -year-long period the children born to foreign mothers increased from $6.6 \%$ of the total number of the born alive in Italy in 2000 to $19.4 \%$ in 2015.

Thanks to the analysed data, one can state that after 1995 the increase of the TFR is certainly attributable to the contribution of foreign women. (Diagrams 3 and 4)

Chart 3 - Born alive in Italy according to the citizenship of their mother

\begin{tabular}{|c|c|c|c|}
\hline Years & Born (A) & $\begin{array}{c}\text { Born to foreign } \\
\text { mother }(\mathrm{B})\end{array}$ & $\begin{array}{c}\text { B/A } \\
(\%)\end{array}$ \\
\hline 2000 & 532,528 & 35,001 & 6.6 \\
2005 & 554,022 & 67,694 & 12.2 \\
2010 & 561,944 & 99,312 & 17.7 \\
2015 & 485,780 & 94,269 & 19.4 \\
\hline
\end{tabular}

Source: Istat

Diagram 3 - Born alive to Italian mother

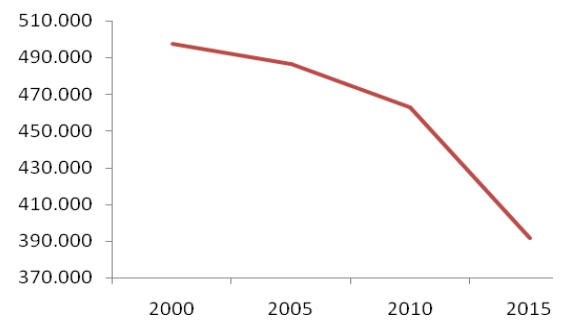

Diagram 4 - Born alive to foreign mother

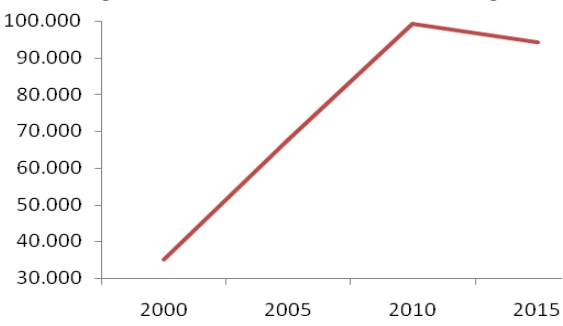

If one considers only the last available TFR value (1.35), this is lower than the substitution one (2.1) that is able to guarantee the generational mobility. Therefore, when a TFR is lower than the threshold level and if one takes only the natural components into account, population is potentially in decline ${ }^{12}$.

If in 2015 due to 485,780 births there was a TFR rate of 1.35 , one wonders how many births are necessary to make the fecundity rate reach the substitution value (2.1) in order to guarantee at least the substitution of the generation of mothers and to lead the Italian population towards stability.

Thanks to the recorded regional TFRs one can indirectly obtain the expected births through:

${ }^{12}$ SACCO, G., SACCO P. (2016). The ageing scenario of the Italian Population ( Vol 12, No 35). Publisher ESI, ISSN: 1857 - 7431 (Online), December, (pp. 1 -15). 


$$
N_{x}^{(\operatorname{exp~ected~})}=2,1 \cdot \frac{f_{x}^{(2015)}}{T F R^{(2015)}} \cdot \bar{F}_{x}^{(2015)}
$$

where $\frac{f_{x}^{(2015)}}{T F R^{(2015)}}$ represents the calendar of fecundity, that is the portion of TFR at different ages, $\bar{F}_{x}$ is the average female population of child-bearing age (15-49 years old) and 2.1 is the threshold level of substitution.

To guarantee at least the substitution of the generation of mothers and to lead the Italian population towards stability, births should increase by $56.1 \%$, which means that the recorded 485,780 births in 2015 should reach 785, 127 (Chart 4).

As the authors expected, the regional analysis concerning the increase of births shows the lowest percentage in Trentino-Alto Adige (28.6\%), where there was the highest TFR level in 2015, and the highest above-mentioned increase in Sardegna (92\%), which confirms the low level of births recorded in 2015 (see Chart 2).

Chart 4- Recorded and expected births - 2015

\begin{tabular}{llll}
\hline Regions & $\begin{array}{l}\text { Recorded } \\
\text { births }\end{array}$ & $\begin{array}{l}\text { Expected } \\
\text { births }\end{array}$ & $\begin{array}{l}\text { Percentage } \\
\text { variation }\end{array}$ \\
\hline Piemonte & 32,908 & 50,845 & 54.5 \\
Valle d'Aosta & 987 & 1,476 & 49.5 \\
Lombardia & 84,149 & 122,833 & 46.0 \\
Trentino-Alto Adige & 10,173 & 13,082 & 28.6 \\
Veneto & 38,961 & 59,173 & 51.9 \\
Friuli-Venezia Giulia & 8,575 & 13,683 & 59.6 \\
Liguria & 10,155 & 16,427 & 61.8 \\
Emilia-Romagna & 35,813 & 53,143 & 48.4 \\
Toscana & 27,494 & 44,484 & 61.8 \\
Umbria & 6,542 & 10,851 & 65.9 \\
Marche & 11,904 & 18,792 & 57.9 \\
Lazio & 48,231 & 76,584 & 58.8 \\
Abruzzo & 10,238 & 16,819 & 64.3 \\
Molise & 2,181 & 3,921 & 79.8 \\
Campania & 51,005 & 80,143 & 57.1 \\
Puglia & 31,577 & 53,310 & 68.8 \\
Basilicata & 4,122 & 7,380 & 79.0 \\
Calabria & 16,376 & 26,681 & 62.9 \\
Sicilia & 43,307 & 67,226 & 55.2 \\
Sardegna & 11,082 & 21,274 & 92.0 \\
Italy & 485,780 & 758,127 & 56.1 \\
\hline
\end{tabular}

Source: Istat 


\section{Variations of average life expectancy at birth}

As far as comparative aims are concerned, the commonest indicator used to calculate the levels of survival is average life expectancy at birth: as this is an indicator that is not influenced by the structure per age, it enables to obtain very satisfying values.

Thanks to the progress in the field of medicine and to the improvements of lifestyles and food, in Italy there have been considerable increases of average life expectancy at birth, the level of which is one of the highest in the member states of the European Union.

As one can infer in detail from the data of Chart 5, in 2015 the countries with the highest average life expectancy at birth for men are Sweden (80.4), Italy (80.1), Spain (80.1) and Luxembourg (80.0).

As for women, the highest values are in Spain (85.7), France (85.5), Luxembourg (84.7) and Italy (84.6). ${ }^{13}$

Chart 5 - Levels of survival in the member states of the European Union in 2015

\begin{tabular}{c|c|c|c|c|c}
\hline Countries & $e_{0}^{M}$ & $e_{0}^{F}$ & Countries & $e_{0}^{M}$ & $e_{0}^{F}$ \\
\hline Austria & 78.8 & 83.7 & Lithuania & 69.2 & 79.7 \\
Belgium & 78.7 & 83.4 & Luxembourg & 80.0 & 84.7 \\
Bulgaria & 71.2 & 78.2 & Malta & 79.7 & 84.0 \\
Cyprus & 79.9 & 83.7 & Netherlands & 79.9 & 83.2 \\
Croatia & 74.4 & 80.5 & Poland & 73.5 & 81.6 \\
Denmark & 78.8 & 82.7 & Portugal & 78.1 & 84.3 \\
Estonia & 73.2 & 82.2 & United Kingdom & 79.2 & 82.8 \\
Finland & 78.7 & 84.4 & Czech Republic & 75.7 & 81.6 \\
France & 79.2 & 85.5 & Romania & 71.5 & 78.7 \\
Germany & 78.3 & 83.1 & Slovak Republic & 73.1 & 80.2 \\
Greece & 78.5 & 83.7 & Slovenia & 77.8 & 83.9 \\
Ireland & 79.6 & 83.4 & Span & 80.1 & 85.7 \\
Italy & 80.1 & 84.6 & Sweden & 80.4 & 84.1 \\
Latvia & 69.7 & 79.5 & Hungary & 72.3 & 79.0 \\
\hline
\end{tabular}

Source: Eurostat

A deep insight into the values of the average life expectancy at birth of males and females from 1974 to 2015 (Chart 6) reveals that in 1974 newborn males and females could expect to live on average until 70 and 76 years old respectively. In 2015 the average life expectancy is 80 years old for males and 85 years old for women.

${ }^{13}$ CAGIANO de AZEVEDO, R. CAPACCI, G. (2004). Invecchiamento e svecchiamento della popolazione europea. Aracne editrice, Roma. 
Chart 6 - Average life expectancy per sex

\begin{tabular}{|c|c|c|c|c|c|}
\hline \multirow[t]{2}{*}{ Years } & \multicolumn{2}{|l|}{$e_{0}$} & \multicolumn{2}{|c|}{$\begin{array}{l}\text { No. indices } \\
1974=100\end{array}$} & \multirow{2}{*}{$\frac{e_{0}^{F}}{e_{0}^{M}} \cdot 100$} \\
\hline & $\mathrm{M}$ & $\mathrm{F}$ & $\mathrm{M}$ & $\mathrm{F}$ & \\
\hline 1974 & 69.6 & 75.9 & 100.0 & 100.0 & 109.0 \\
\hline 1984 & 72.0 & 78.6 & 103.4 & 103.6 & 109.2 \\
\hline 1994 & 74.4 & 80.8 & 106.9 & 106.4 & 108.6 \\
\hline 2004 & 77.9 & 83.6 & 111.9 & 110.1 & 107.3 \\
\hline 2015 & 80.1 & 84.6 & 115.1 & 111.5 & 105.6 \\
\hline
\end{tabular}

Source: Istat

During the period of time under study the average life expectancy at birth increased by $15.1 \%$ for males and by about $12.0 \%$ for females. There is therefore a higher increase of survival for males that can be inferred also from the values of the excess mortality of males.

In order to highlight the interesting territorial differences between sexes, the authors created Chart 7: they compared the values of the average life expectancy at birth in the Italian regions, for males and females respectively, as well as the variation indices and the ratio between the levels of the average life expectancy of the two sexes, which can be identified as the male excess mortality.

Chart 7 - Average life expectancy at birth per sex and regions. 1974-2015

\begin{tabular}{|c|c|c|c|c|c|c|c|c|}
\hline \multirow{3}{*}{ Regions } & \multicolumn{4}{|c|}{ Values of $e_{0}$} & \multirow{2}{*}{\multicolumn{2}{|c|}{$\begin{array}{l}\text { Indices } \\
\text { numbers } \\
1974=100\end{array}$}} & \multirow{2}{*}{\multicolumn{2}{|c|}{$\frac{e_{0}^{F}}{e_{0}^{M}} \cdot 100$}} \\
\hline & \multicolumn{2}{|l|}{1974} & \multicolumn{2}{|c|}{2015} & & & & \\
\hline & $\mathrm{M}$ & $\mathrm{F}$ & $\mathrm{M}$ & $\mathrm{F}$ & $\mathrm{M}$ & $\mathrm{F}$ & 1974 & 2015 \\
\hline Piemonte $^{14}$ & 76.8 & 82.7 & 79.9 & 84.5 & 104.0 & 102.2 & 107.7 & 105.8 \\
\hline Valle d'Aosta & 74.8 & 82.2 & 78.7 & 83.6 & 105.2 & 101.7 & 109.9 & 106.2 \\
\hline Lombardia & 68.1 & 75.5 & 80.6 & 85.1 & 118.4 & 112.7 & 110.9 & 105.6 \\
\hline Trentino-Alto Adige & 68.4 & 75.7 & 81.0 & 85.7 & 118.4 & 113.2 & 110.7 & 105.8 \\
\hline Veneto & 68.6 & 76.4 & 80.6 & 85.3 & 117.5 & 111.6 & 111.4 & 105.8 \\
\hline Friuli-Venezia Giulia & 67.8 & 76.1 & 79.9 & 85.0 & 117.8 & 111.7 & 112.2 & 106.4 \\
\hline Liguria & 69.1 & 75.9 & 79.9 & 84.6 & 115.6 & 111.5 & 109.8 & 105.9 \\
\hline Emilia-Romagna & 69.9 & 76.7 & 80.9 & 84.9 & 115.7 & 110.7 & 109.7 & 104.9 \\
\hline Toscana & 71.1 & 77.5 & 80.6 & 85.1 & 113.4 & 109.8 & 109.0 & 105.6 \\
\hline Umbria & 71.4 & 77.4 & 80.6 & 85.3 & 112.9 & 110.2 & 108.4 & 105.8 \\
\hline Marche & 71.6 & 77.2 & 80.7 & 85.3 & 112.7 & 110.5 & 107.8 & 105.7 \\
\hline Lazio & 70.6 & 76.6 & 80.1 & 84.5 & 113.5 & 110.3 & 108.5 & 105.5 \\
\hline Abruzzo & 77.4 & 83.2 & 80.1 & 84.6 & 103.5 & 101.7 & 107.5 & 105.6 \\
\hline Molise & 77.7 & 83.4 & 79.6 & 84.8 & 102.4 & 101.7 & 107.3 & 106.5 \\
\hline Campania & 68.8 & 73.9 & 78.3 & 82.8 & 113.8 & 112.0 & 107.4 & 105.7 \\
\hline
\end{tabular}

${ }^{14}$ As for Piemonte, Valle d'Aosta, Abruzzo and Molise, the levels of the average life expectancy at birth for males and females that are shown in the chart in the year 1974 actually refer to the year 2002, because in the previous period the levels of their average life expectancy at birth were calculated as coupled regions (Piemonte + Valle d'Aosta and Abruzzo + Molise). For this reason the available data for the single regions only start from 2002. 


\begin{tabular}{lllllllll} 
Puglia & 70.8 & 75.6 & 80.3 & 84.5 & 113.4 & 111.8 & 106.8 & 105.2 \\
Basilicata & 71.3 & 75.6 & 79.7 & 84.4 & 111.8 & 111.6 & 106.0 & 105.9 \\
Calabria & 71.7 & 76.1 & 79.6 & 84.3 & 111.0 & 110.8 & 106.1 & 105.9 \\
Sicilia & 71.1 & 75.4 & 79.4 & 83.4 & 111.7 & 110.6 & 106.0 & 105.0 \\
Sardegna & 71.1 & 76.6 & 79.8 & 84.8 & 112.2 & 110.7 & 107.7 & 106.3 \\
Italy & 69.6 & 75.9 & 80.1 & 84.6 & 115.1 & 111.5 & 109.0 & 105.6 \\
\hline
\end{tabular}

Source: Authors' elaborations based on Istat data.

If we do not consider the data concerning Piemonte, Valle d'Aosta, Abruzzo and Molise for the reasons explained in footnote 2, in 1974 the levels of the average life expectancy at birth in chart 7 show that the levels of males are slightly lower in the northern regions, while they are higher in the central and southern ones.

In 2015 the average life expectancy at birth for males moderately increased in the central and northern regions compared with that of the southern ones. As for females, there are nor remarkable gaps.

If one compares the average life expectancy at birth of males through the variation indices in the two years under study, one infers that it increases in the northern regions where, in 1974, its levels were slightly lower. This means that the average life expectancy at birth of males shows a decreased gap between northern and southern regions.

As for the female sex, if one compares the values of the average life expectancy at birth in 1974 with the variation levels in 2015, the regional differences do not show remarkable situations, which therefore highlights an unchanged condition.

In general terms, males have a higher death risk than females as one can infer from the excess mortality of males: in 1974 it was higher in the northern regions, while in 2015 there are considerable lower values in all regions, thus stressing a higher survival of males.

\section{Variation of death risk per age}

The comparison between the levels of the average life expectancy at birth in the whole country in 1974 and 2015 (Chart 7) both for males (69.6 and 80.1 ) and females (75.9 and 84.6) shows a longer life of males (10.5 years) and females (8.7 years).

Longer life rates are determined by the variations of death risk at different ages and, in the case under study, by the influence that the contraction of mortality has exerted on the dynamics of the levels of the average life expectancy at birth for males and females. For this reason one needs to evaluate how some age groups have contributed to the increase of the average life expectancy at birth for both sexes.

In order to determine the influence exerted by the mortality per age on the variation of the average life expectancy at birth, the age groups that will 
be analysed are those concerning the following ages: 0-5 (infantile), 5-25 (infantile and juvenile), 25-65 (adult). 65+ (elderly).

The analysis will be made for males and females separately, the suitable mortality tables issued by Istat will be used and the time under study will be divided into two periods: 1974-1994 and 1994-2015 in order to compare the two epochs.

Once it is determined that the population is divided into the above mentioned 4 age groups, the average life expectancy at birth in any population and in any moment will be :

$$
\begin{aligned}
& e_{0}=e_{(0,5)}+p_{(0,5)} \cdot e_{(5,25)}+p_{(0,25)} \cdot e_{(25,65)}+p_{(0,65)} \cdot e_{(65, \omega)} \\
& \quad \text { where } \\
& e_{(x, y)}=\frac{e_{x} \cdot l_{x}-e_{y} \cdot l_{y}}{l_{x}}=\frac{T_{x}-T_{y}}{l_{x}}
\end{aligned}
$$

represents the average number of years that every individual surviving the age $x$ will live between the two birthdays $x$ and $y$ while $p_{(x, y)}$ represents the possibility that individuals whose age is $x$ can be still alive when their age is $y$.

In order to determine how the single age groups contributed to the increase of the average life expectancy at birth, one needs to replace the mortality of the age groups at time 0 with that of the age groups at time $t$.

In the case under study the variations of the average life expectancy at birth determined by the mortality concerning the different age groups will be:

$$
\begin{aligned}
& V_{(0,5)}=e_{(0,5)}^{t}+p_{(0,5)}^{t} \cdot e_{(5,25)}+p_{(0,5)}^{t} \cdot p_{(5,25)} \cdot e_{(25,65)}+p_{(0,5)}^{t} \cdot p_{(5,65)} \cdot e_{(65, \omega)}-e_{0} \\
& V_{(5,25)}=e_{(0,5)}+p_{(0,5)} \cdot e_{(5,25)}^{t}+p_{(0,5)} \cdot p_{(5,25)}^{t} \cdot e_{(25,65)}+p_{(0,5)} \cdot p_{(5,25)}^{t} \cdot p_{(25,65)} \cdot e_{(65, \omega)}-e_{0} \\
& V_{(25,65)}=e_{(0,5)}+p_{(0,5)} \cdot e_{(5,25)}+p_{(0,25)} \cdot e_{(25,65)}^{t}+p_{(0,25)} \cdot p_{(25,65)}^{t} \cdot e_{(65, \omega)}-e_{0} \\
& V_{(65, \omega)}=e_{(0,5)}+p_{(0,5)} \cdot e_{(5,25)}+p_{(0,25)} \cdot e_{(25,65)}+p_{(0,65)} \cdot e_{(65, \omega)}^{t}-e_{0}
\end{aligned}
$$

while the surplus, which tallies with the combined effect of the mortality decrease of the different ages, will be:

$$
V_{(0, \omega)}=\left(e_{0}^{t}-e_{0}\right)-\left(V_{(0,5)}+V_{(5,25)}+V_{(25,65)}+V_{(65, \omega)}\right)
$$

Thanks to these calculations we obtain the variations of the average life expectancy at birth during the two periods, 1974-1994 and 1994-2015, due to the dynamics of mortality related to the age groups under study and to the combined effect (Chart 8).

From the data of Chart 8 one can infer that in the first twenty-year period the increase of the value of the average life expectancy at birth was slightly higher for the female sex (5 years) compared with the male one (4.80 years). On the contrary, in the second twenty-year period the situation is 
reversed: the males have a longer life (5.70 years) compared to the females' one (3.77 years).

Chart 8 - Variations of the average life expectancy at birth

\begin{tabular}{c|c|c|c|c|}
\hline \multirow{2}{*}{ Age classes } & \multicolumn{2}{|c|}{$1974-1994$} & \multicolumn{2}{c|}{$1994-2015$} \\
\cline { 2 - 5 } & $\mathrm{M}$ & $\mathrm{F}$ & $\mathrm{M}$ & $\mathrm{F}$ \\
\hline $0-5$ & 1.51 & 1.24 & 0.41 & 0.38 \\
$5-25$ & 0.19 & 0.37 & 0.40 & 0.15 \\
$25-65$ & 1.40 & 1.07 & 2.03 & 0.83 \\
$65+$ & 1.49 & 2.32 & 2.54 & 2.30 \\
Combined effect & 0.21 & 0.00 & 0.32 & 0.11 \\
\hline$e_{0}^{t}-e_{0}$ & 4.80 & 5.00 & 5.70 & 3.77 \\
\hline
\end{tabular}

Source: Authors' elaboration based on Istat data

The class group that most contributed to a longer average life expectancy at birth during the first twenty-year period was the infantile class (0-5 years) with its $31.46 \%$ for males, and the $65+$ class with its $46.40 \%$ for females.

During the second twenty-year period the increase both for males and females is certainly due to the elderly class $(65+)$, whose increase was equal to $44.56 \%$ and $61.01 \%$ respectively (Chart 9 ). ${ }^{15}$

Briefly, it can be stated that the contribution given by the infantile ages to the increase of the average life expectancy at birth has been decreasing over the years because this is basically due to the other age classes. Moreover, this contribution has been higher for the male $\operatorname{sex}^{16}$.

Chart 9 - Incidence of the variations of the average life expectancy at birth

\begin{tabular}{c|c|c|c|c|}
\hline \multirow{2}{*}{ Age classes } & \multicolumn{2}{|c}{$1974-1994$} & \multicolumn{2}{c|}{$1994-2015$} \\
\cline { 2 - 5 } & $\mathrm{M}$ & $\mathrm{F}$ & $\mathrm{M}$ & $\mathrm{F}$ \\
\hline $0-5$ & 31.46 & 24.80 & 7.19 & 10.08 \\
$5-25$ & 3.96 & 7.40 & 7.02 & 3.98 \\
$25-65$ & 29.17 & 21.40 & 35.61 & 22.02 \\
$65+$ & 31.04 & 46.40 & 44.56 & 61.01 \\
Combined effect & 4.37 & 0.00 & 5.62 & 2.91 \\
\hline Total & 100.00 & 100.00 & 100.00 & 100.00 \\
\hline
\end{tabular}

Source: Authors' elaboration based on Istat data

\section{Final considerations}

The analysis of demographic structural endogenous factors, such as fecundity and mortality, during their time evolution enables the observation of

15 BUTLER, R.N. (2008). The longevity revolution: the benefits and challenges of living a long life. New York: Public Affairs.

16 CASELLI G., EGIDI V. (2011). Una vita più lunga e più sana. In: Golini A., Rosina A. (a cura di), Il secolo degli anziani: Come cambierà l'Italia. Il Mulino, Bologna, (pp. 29-45).

SANDERSON, W., SCHERBOV S. (2007). A new perspective on population aging. Demographic Research 16, (pp. 27-58). 
the effects produced in the Italian social context as far as the ageing of population is concerned.

A deeper insight into the phenomenon of fecundity reveals that the past two decades have been characterized by a reversal of the fecundity geography: the central and northern regions in Italy have reached and exceeded the values of the southern regions, which, in turn, have suffered a constant period of decline. This reversal is the effect of the births of the foreign population that is mostly concentrated in the North. Thanks to their 1.63 children per woman, Trentino-Alto Adige is the most prolific region of the country. In every northern region, excepting Liguria (1.30 children), fecundity rates are higher than the national average. The whole north of Italy (1.41 children per woman) is the sector with the highest fecundity rate, while in the South no region has a fecundity rate exceeding the national average. In regions like Sicilia and Campania, which were once considered the reproductive area of the country, the fecundity rate in 2015 is 1.35 and 1.34 per woman respectively. Moreover, in other southern regions there are still deep-rooted low fecundity rates: in Molise, Basilicata and Sardegna the level of 1.2 children per woman has not been reached for a long time.

However, the decrease of births in 2015 is a consequence similar to an analogous action of reproductive reduction carried out by both Italian and foreign women. In actual fact, the fecundity of foreign women keeps on increasing the general fecundity but at the same time it is in decline because it goes below the threshold level of 2 children per woman. It is highly desirable that suitable family policies enable the increase of births, because this trend is still negative on the basis of the data published by Istat in 2016.

Life expectancy is a measure of the social, environmental and health state in which a population lives. It is in inverse relation to the mortality rate of a population as it represents a useful demographic index used to evaluate the state of development of a country. In 2015 the survival conditions of the Italian population improved and there was a new increase of life expectancy at birth. Men exceed the threshold of 80 years old and women that of 85 years old. Therefore, the dynamics of survival analysed in the past few years confirms the decrease of women's advantage.

As a consequence of the above-mentioned trend, in the Italian demographic situation a weak natural dynamics is looming: it shows a country going towards territorial models that are sufficiently alike. Unfortunately, the first consequent critical state will be the increase of generational inequalities that, according to the last report of OECD (2017), will widen the gap between the old and new generations as far as social inequalities are concerned. As Italy lacks a strong network of social security, wage and social security inequalities are expected (Preventing Ageing Unequally). 


\section{References:}

1. CAGIANO de AZEVEDO, R. CAPACCI, G. (2004). Invecchiamento e svecchiamento della popolazione europea. Aracne editrice, Roma.

2. CASELLI G., EGIDI V. (2011). Una vita più lunga e più sana. In: Golini A., Rosina A. (a cura di), Il secolo degli anziani: Come cambierà l'Italia. Il Mulino, Bologna, (pp. 29-45).

3. BUTLER, R.N. (2008). The longevity revolution: the benefits and challenges of living a long life. New York: Public Affairs.

4. EUROSTAT, ec. europa.eu/eurostat/data/data base.

5. ISTAT, (2016). Indicatori demografici - Stime per l'anno 2015.

6. ISTAT, (2017). Indicatori demografici - Stime per l'anno 2016.

7. LIVI BACCI, M. (1999). Introduzione alla Demografia. Loescher Ed.

8. SACCO, G., SACCO P. (2016). The ageing scenario of the Italian Population ( Vol 12, No 35). Publisher ESI, ISSN: 1857 - 7431 (Online), December, (pp. 1 -15).

9. SANDERSON, W., SCHERBOV S. (2007). A new perspective on population aging. Demographic Research 16, (pp. 27-58). 